\title{
Adélie penguin (Pygoscelis adeliae) survival rates and their relationship to environmental indices in the South Shetland Islands, Antarctica
}

\author{
Jefferson T. Hinke $\cdot$ Susan G. Trivelpiece $\cdot$ \\ Wayne Z. Trivelpiece
}

Received: 2 April 2014/Revised: 13 August 2014/Accepted: 21 August 2014/Published online: 11 September 2014

(C) The Author(s) 2014. This article is published with open access at Springerlink.com

\begin{abstract}
Seabird life history is typified by low fecundity, high adult survival rates, and relatively long lives. Such traits act as buffers, enabling persistence of populations under variable environmental conditions. Numerous studies, however, have suggested strong sensitivity of seabirds to environmental variability. In the Antarctic Peninsula region, for example, Adélie penguin (Pygoscelis adeliae) populations have declined during the last three decades, attributed largely to rapid changes in environmental conditions and food availability. We use 30 years of markrecapture data from known-age individuals in the South Shetland Islands and capture-mark-recapture models to estimate survival rates with respect to such environmental variation. We investigated specifically whether negative trends in survival rates were evident and whether indices of global, regional, and local environmental conditions considered important for Adélie penguin survival explained the variability in survival rates. Overall, negative trends in juvenile survival were evident, but adult survival rates exhibited high interannual variability. Indices of sea ice extent had the strongest correlations with survival rates, particularly Weddell Sea ice extent during spring among adults $(r=0.62)$ and during winter for juveniles $(r=0.46)$. An analysis of deviance, however, suggested that single environmental covariates explained $<30 \%$ of
\end{abstract}

Electronic supplementary material The online version of this article (doi:10.1007/s00300-014-1562-2) contains supplementary material, which is available to authorized users.

J. T. Hinke $(\bowtie) \cdot$ S. G. Trivelpiece $\cdot$ W. Z. Trivelpiece Antarctic Ecosystem Research Division, Southwest Fisheries

Science Center, National Marine Fisheries Service,

National Oceanic and Atmospheric Administration, 8901 La Jolla Shores Drive, La Jolla, CA 92037, USA

e-mail: Jefferson.Hinke@noaa.gov the observed variation in the full mark-recapture models. Despite positive effects of sea ice extent on survival rates of Adélie penguins, limited explanatory power of several environmental conditions previously identified as important for Adélie penguin survival underscores the difficulty of predicting future population responses in this region of rapid environmental change.

Keywords Demography $\cdot$ Life history $\cdot$ Seabird $\cdot$ Markrecapture

\section{Introduction}

Life history traits that include low fecundity, high adult survival rates, and relatively long lives can act as buffers that enable persistence of populations under variable environmental conditions (Stearns 1992). Many seabirds display such life history traits, but observed variation and directional change in environmental conditions have caused changes in phenology, breeding and foraging ranges, and population trends of numerous seabirds (Veit et al. 1996; Sandvik et al. 2005; Barbraud and Weimerskirch 2006; Devney et al. 2009). In particular, long-term data on Antarctic seabirds dependent on sea ice habitats, including emperor (Aptenodytes forsteri) and Adélie penguins (Pygoscelis adeliae), and snow petrels (Pagodroma nivea) suggest that variation in the seasonal duration and spatial extent of winter sea ice can be important drivers of population change (Croxall et al. 2002; Jenouvrier et al. 2005; Emmerson and Southwell 2011). Demographic models that link vital rates to environmental drivers (e.g., Jenouvrier et al. 2009) and habitatassociation models (e.g., Ainley et al. 2010) suggest that continued warming and loss of sea ice in Antarctica may hasten declines in the abundance of ice-obligate species. 
During the last few decades, the western Antarctic Peninsula (WAP) region has been recognized as one of the most rapidly changing areas on the planet. The WAP region is characterized by increases in air and sea temperatures (Turner et al. 2005a; Meredith and King 2005), a shrinking duration of winter sea ice coverage (Stammerjohn et al. 2008a; Turner et al. 2009), an increased frequency of storms with major precipitation events (Turner et al. 2005b), and greater accumulation rates of snow (Thomas et al. 2008). Satellite-based observations of ocean color have revealed potential declines in marine primary production (Montes-Hugo et al. 2009), while long-term net tow survey data suggest a possibly $80 \%$ decline in the abundance of Antarctic krill (Euphausia superba; Atkinson et al. 2004), the main food item for most seabirds, marine mammals, and fishes in the WAP region. As ice-obligate, krill-dependent predators that require snow-free ground for successful breeding, Adélie penguin populations would be expected to decline under such changing environmental conditions (Fraser et al. 1992; Trivelpiece et al. 2011). Monitoring data in the WAP region support that expectation (Hinke et al. 2007; Lynch et al. 2008). In particular, reductions in Adélie penguin population size and recruitment to the breeding population have been correlated with variation in winter sea ice extent and krill demography throughout their circumpolar range (Trathan et al. 1996; Wilson et al. 2001; Fraser and Hofmann 2003; Jenouvrier et al. 2006; Hinke et al. 2007). The weight of evidence suggests that Adélie penguins are sensitive to environmental variability.

A more thorough understanding of how environmental variability, including directional changes (e.g., climate warming) and changes in the variance of environmental conditions (e.g., a changing frequency or magnitude of storm events), have influenced Adélie penguin populations is facilitated by long-term field studies of uniquely marked individuals. Such studies have been conducted throughout the Adélie penguin breeding range and have enabled the estimation of survival rates with respect to environmental conditions. In east Antarctica, survival rates of Adélie penguins have been linked to annual sea ice dynamics and large-scale atmospheric indices such as the Southern Oscillation Index (SOI) (Jenouvrier et al. 2006; Emmerson and Southwell 2011). In the Ross Sea, relationships between environmental covariates and survival rates include either nonlinear effects of sea ice on adult survival rates (Ballerini et al. 2009), potential lagged effects of ice extent on juvenile survival rates (Wilson et al. 2001), or no significant effects of environmental conditions (Lescroël et al. 2009). Thus, throughout the range of Adélie penguins, different relationships between demographic rates and environmental conditions have been identified.
A prior study of Adélie penguin demography in the South Shetland Islands, a more northerly colony than those studied in east Antarctica or the Ross Sea, reported that recruitment, estimated as the proportion of a banded cohort that returned to the natal colony, had declined by up to $90 \%$ during the period 1981 to 2004 (Hinke et al. 2007). The authors suggested that the decline in recruitment was due to negative trends in juvenile survival rates. However, the recruitment rates reported by Hinke et al. (2007) did not provide a full account of survival rates, because survival and recapture probabilities are confounded when a proportional return rate is calculated (Lebreton et al. 1992). Further, the recruitment index was based on the first return of any bird to its natal colony, irrespective of age. Thus, information on trends and variation of survival rates for particular age classes or life stages of Adélie penguins, and their relationship with specific environmental variables in the rapidly changing South Shetland Islands region, remains unreported. This study estimates Adélie penguin survival rates to improve understanding of factors affecting Adélie penguin population declines near the northern extent of their range.

A robust approach for estimating survival rates with respect to environmental drivers rests on capture-markrecapture (CMR) methodology (Lebreton et al. 1992). Here, we apply CMR methods to long-term data from banded Adélie penguins to estimate survival rates during a period of rapid environmental change in the WAP region. We ask whether the CMR data provide support for declines in juvenile survival rates, declines in adult survival rates, or increased variability in survival rates. We also examine the ability of environmental indices to explain variation in estimated survival rates through an integrated CMR modeling approach (Lebreton et al. 1992; Grosbois et al. 2008).

\section{Materials and methods}

Study site and Adélie penguin life cycle

Long-term CMR data from known-age Adélie penguins were collected at the Copacabana penguin colony within Admiralty Bay, King George Island, South Shetland Islands $\left(62^{\circ} 10^{\prime} \mathrm{S}, 58^{\circ} 30^{\prime} \mathrm{W}\right.$; Fig. 1). Adult Adélie penguins occupy nests within the colony from October to February, and all mark and recapture effort occurred during this austral summer breeding season. After the breeding season, adult Adélie penguins migrate to areas covered with pack ice for the annual full-plumage molt and foraging during the austral winter. Based on tracking data reported by Clarke et al. (2003), we assume that fledgling Adélie penguins use similar over-winter areas as adults. We note that adult Adélie penguins tracked during the non-breeding 


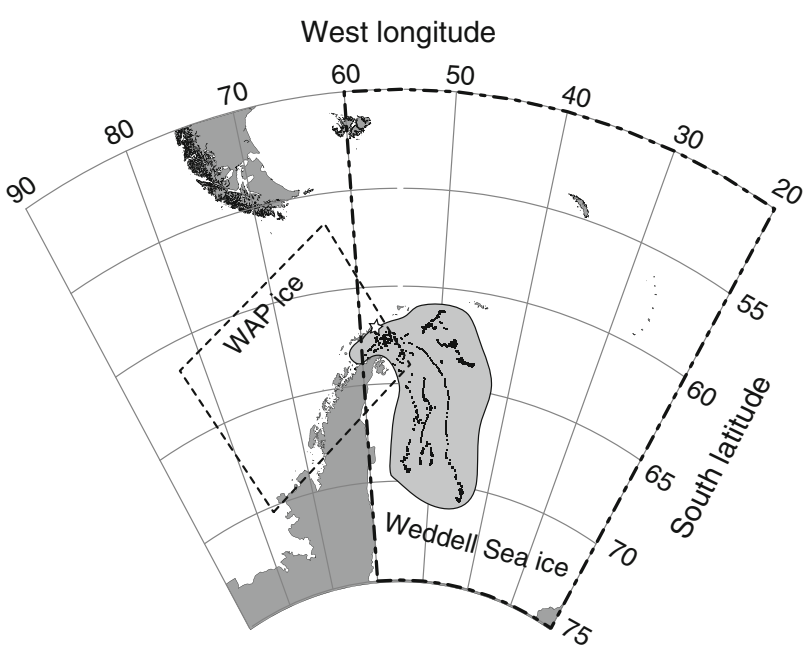

Fig. 1 Map of study area and distribution of available ARGOS-based satellite tracking data (black dots, 1997-2012) of P. adeliae from the Copacabana colony (white star) with location estimates from February through October. Boundaries of the areas used to calculate sea ice indices are included as dashed lines (western Antarctic Peninsula) or dash-dot lines (Weddell Sea)

period from the Copacabana colony used areas within the Bransfield Strait and Weddell Sea (WZT, unpublished data, Fig. 1).

Initial release and subsequent recapture of banded individuals

We used 30 years of data from birds that were banded from the 1981/82 through 2010/11 austral summer field seasons. Each year between 248 and 1,500 chicks were marked on the left flipper with uniquely numbered, field-readable aluminum band or, in later years, a stainless steel band. Tags were distributed throughout the breeding colony, and the number of tags released each year was adjusted periodically to track long-term declines in the breeding population. Chicks were banded at an age of approximately 5 weeks, when small groups of chicks were captured with either hand nets or corralled with a modified beach seine. All birds were released after banding. At the time of banding, the sex of individuals was not determined.

During subsequent years, any observation (recapture) of a known-age penguin in the colony throughout the breeding season was recorded. In general, recapture effort was similar each year and included daily visits to the colony to scan peripheral and central nesting areas for banded individuals and systematic searches along beaches and areas adjacent to the colonies where penguins often congregated. Note that all recaptures were visual, made with binoculars or by eye, to confirm the band number and the presence of a known individual in the colony; generally, no physical handling of banded birds occurred after initial band placement. On rare occasions, partially open or improperly fitted bands were repaired during the study. In total, the CMR data consist of 7,601 recaptures of 2,846 individual birds banded as chicks.

\section{Band loss}

An important assumption in CMR studies is that marks (bands) are not lost from the population. Losing marks, whether from permanent emigration or tag shedding, can bias estimates of survival. We have no data to assess the magnitude of potential permanent emigration from the study site because no monitoring for banded individuals was systematically conducted anywhere other than the natal banding colonies. We note that, where estimable, emigration rates exhibited by Adélie penguins are relatively low (Dugger et al. 2010), and the site fidelity exhibited by Adélie penguins makes them model organisms for demographic study. With respect to birds losing their bands, the bias caused by band loss is typically small relative to the standard error of the estimated survival rate (Nelson et al. 1980). However, because the type of flipper band changed from aluminum bands (used from 1984/85 to 1998/99) to stainless steel (used from 1997/98 to 2010/11) with 2 years of overlapping releases, it was necessary to establish whether both band types had similar loss rates, thus similar potential bias on survival. We used data from two independent banding studies on adult Adélie penguins to examine potential differences in band loss rates for each band type and to determine whether accounting for band type in models of survival and recapture was warranted. The first banding study was conducted over one winter period from 2000/01 to 2001/02 and used 200 adult males in a double banding study to directly estimate band loss rates. We also examined a 13-year data set of singly banded individuals to examine differences in overwinter return rates of breeding male and female Adélie penguins marked with either aluminum or stainless steel bands. Summary information from these two studies (Online Resource 1) supports the inclusion banding effects in the CMR models.

\section{Estimates of survival and recapture probabilities}

Survival rates of juvenile penguins may differ from adults and so we estimated survival rates for alternative classifications of juvenile and adult age classes (defined below). We used Program MARK (White and Burnham 1999), interfaced with R (version 2.15., R Core Team 2012) via the RMark package (Laake 2013). MARK and RMark are flexible, purpose-built software that readily enable analysis of CMR data via construction of multiple competing models to estimate survival and recapture probabilities with maximum likelihood methods. 
The first step toward estimating survival and recapture probabilities from CMR data is to identify a global model that adequately fits the data and to which more parsimonious models can be compared. Because our focus was on variation in survival among age classes, we chose a global model with time- and age-dependent effects on survival $\left(\varphi_{a * t}\right)$ and recapture probability $\left(p_{a * t}\right)$ for all ages, denoted by subscript $a$. Additionally, we included an additive effect of band type on survival and recapture probability in the global model to account for potential differences in survival and recapture rates arising from different band types (Online Resource 1).

Goodness of fit for the chosen global model $\left(\varphi_{a * t+\text { band }} \cdot p_{a * t+\text { band }}\right)$ was assessed using a bootstrapping procedure implemented in Program MARK (White and Burnham 1999). The ratio of observed model deviance to the mean bootstrapped deviance provides an estimator of the variance inflation factor, $\hat{c}$, and indicates the degree of model fit. Generally, values of $\hat{c}<3$ are considered acceptable (Lebreton et al. 1992) for further model selection to proceed.

\section{Simplifying the CMR model structure}

The global model with full age structure was simplified by considering alternative age classes, denoted with subscript $a c$, for both survival $\left(\varphi_{\mathrm{ac}}\right)$ and recapture probabilities $\left(p_{\mathrm{ac}}\right)$. For survival rates, we considered alternative 'juvenile,' 'pre-breeder,' and 'adult' age classes. The groupings are biologically appropriate given that Adélie penguins typically first return to natal colonies during the second year of life, mature by age 3, and initiate breeding by age 4 . Additionally, breeding activity may reduce adult survival rates (Lescroël et al. 2009); thus a pre-breeding age class (mature, but not breeding) may exhibit different survival rates than breeding-age adults. We defined four different age-class models to include such demographic considerations. The first candidate model included survival rates for a juvenile age class (age 0-2) and an adult age class (ages $2+)$, denoted $\varphi_{\text {ac1 }}$. The second candidate model consisted of a juvenile age class (age 0 to 3 ) with an adult age class (age $3+$ ), denoted $\varphi_{\text {ac2 }}$. The last two included a juvenile age class for survival from age 0 to 2 , and either a prebreeding age class for survival from 2 to 3 or from 2 to 4 , with adult age classes for survival of all birds aged $3+$ $\left(\varphi_{\mathrm{ac} 3}\right)$ or $4+\left(\varphi_{\mathrm{ac} 4}\right)$, respectively.

We considered three different age classes for estimating recapture probabilities. All models included a juvenile stage for the recapture of age 1 animals to account for the fact that essentially 0 animals are recaptured at age 1 . The three candidate recapture models therefore included a 2stage model for recapture of juveniles (age 1) and all older ages (ages $2+$ ), denoted $p_{\text {ac1 }}$, a 3-stage model, $p_{\text {ac2 }}$, for juveniles (age 1), pre-breeders (age 2), and adults (ages $3+$ ), and an 4-stage model, $p_{\mathrm{ac} 3}$, for recapture of juveniles (age 1), two pre-breeder stages for recapture of age 2 and age 3 birds, respectively, and adults (ages 4+). Exploratory analyses with more resolution in older age classes (e.g., to account for potential senescence) suggested that limiting the models of survival and recapture probability to a generic adult stage, as defined above, was sufficient. We note that the age classes used to model survival rates differed from the age classes used to model recapture rates in the final set of model reported here.

In CMR studies, some individuals may be more (or less) likely to be recaptured than others based on their prior recapture history. Such behavior, termed trap dependence, can violate the assumption of equal recapture probability of all banded individuals (Pradel 1993). An individual's prior encounter history, however, can be used as a covariate for recapture probability (Sandland and Kirkwood 1981; Lebreton et al. 1992) to account for the possibility that individuals encountered alive previously may be more (or less) likely to be recaptured again. We included trapdependent effects on recapture probabilities, denoted with subscript $t d$, in the model selection process. Note that individual-level covariates like trap dependence cannot be included in bootstrap goodness of fit tests, described above, for the global model (Cooch and White 2013). Because trap dependence was likely to be important in the data (i.e., improving model fit), but unable to be assessed directly during goodness of fit testing, we calculated post hoc model comparison tables using estimates for $\hat{c}$ ranging from 1.5 to 3 to investigate the sensitivity of the model selection process.

Potential time-dependent effects on survival and recapture rates were considered as either interacting with age class or additive for all models. Models with and without the additive effects of trap dependence on recapture probability were also compared for assessing improvement of model performance. All combinations of age class, time, band, and trap-dependence effects of the candidate models $(N=384)$ were fit to the $\mathrm{CMR}$ data and ranked via Akaike Information Criterion (AIC; Akaike 1973).

Environmental correlates of survival and recapture probability

We examined the role of six candidate environmental correlates of penguin survival and recapture, along with a combined index constructed with a principal components analysis. The chosen variables covered a time span of 1982 through 2011 and included indices of large-scale atmospheric forcing (Southern Oscillation Index (SOI) and the Southern Annular Mode (SAM), a local index of physical habitat (sea ice extent) during the non-breeding season 
(March-November) in the WAP region, a regional index of sea ice extent for the non-breeding season across the entire Weddell Sea, and local measures of environmental conditions (spring temperatures and precipitation). These six environmental variables have been implicated previously as factors affecting Adélie population dynamics and survival throughout much of their breeding range (Forcada and Trathan 2009; Jenouvrier et al. 2009), and we have selected them to examine their utility for explaining variation in survival rates in a northern breeding population studied here.

In the Southern Ocean, the SOI and the SAM are important drivers of environmental variability whose effects on sea ice dynamics (Kwok and Comiso 2002) and temperatures (Turner 2004) have been correlated with variation in penguin populations throughout Antarctica (Forcada and Trathan 2009). We used an annual average of monthly values of the SOI index available at the Australian Bureau of Meteorology (http://www.bom.gov.au/climate/ current/soihtm1.shtml, accessed August 21, 2012). Likewise, recent trends in the SAM index, which characterizes the latitudinal pressure gradient between Antarctic and subpolar latitudes, have been implicated in the accelerated rate of warming in the WAP region (Kwok and Comiso 2002) resulting in a loss of sea ice, hence foraging area during winter for Adélie penguins. We used the SAM index values, available from the British Antarctic Survey (http:// www.nerc-bas.ac.uk/icd/gjma/sam.html, accessed August 21, 2012), for the winter period (June, July, and August). The winter SAM index has exhibited the strongest annual trend, as compared to the other seasons, and is correlated with the overall increase in the SAM, during the study period.

Seasonal development and movement of pack ice largely dictate habitat availability for Adélie penguins during winter and may influence general ecosystem productivity that supports prey resources. We used two indices of of sea ice extent anomalies, based on the methods of Cavalieri et al. (1999), as an index of physical conditions that are likely to affect ice-obligate Adélie penguins. The first provides a index of ice conditions in the WAP region, as described by Hewitt (1997), where sea ice extent and duration have decreased markedly in recent years (Stammerjohn et al. 2008a). The WAP index estimates winter sea ice coverage over an area of $1.25 \times 10^{6} \mathrm{~km}^{2}$ that includes portions of the western Weddell Sea, eastern Bellingshausen Sea, Bransfield Strait, and southern Drake's Passage (Fig. 1). The WAP index provides partial coverage of the wintering areas used by birds from the study colony, but also represents ice cover in an important source areas for prey resources in the Antarctic Peninsula region region. We also used an index of sea ice extent anomalies that integrates the entire Weddell Sea basin (Fig. 1), whose margins are populated by roughly $30 \%$ of the worldwide Adélie penguin population (Ainley 2002) The ice area in this index provides coverage for the main molting and wintering habitats. Data for the Weddell Sea ice extent anomalies are derived from all ice-covered areas between $60^{\circ} \mathrm{W}$ and $20^{\circ} \mathrm{W}$ longitude (Cavalieri and Parkinson 2008) and is available online from the National Snow and Ice Date Center (http://nsidc.org/). For both indices of ice extent, we calculated annual mean values for the austral autumn (March-May), winter (June-August), and spring (September-November).

Local weather conditions, such as air temperature and precipitation, affect breeding chronologies and breeding success of Adélie penguins (Boersma 2008; Hinke et al. 2012). Here, we include such local weather conditions to ask whether annual survival and recapture rates are also affected by local weather conditions. Following Hinke et al. (2012), we used mean spring (September-November) temperatures and total spring precipitation amounts observed at Bellingshausen Station, a Russian research station located approximately $22 \mathrm{~km}$ southwest of the study colony. Data were acquired online at http://www. aari.aq, accessed August 21, 2012.

All the above-mentioned covariates were combined in a principal component analysis to examine whether integrated indices of environmental conditions provided useful predictor of survival and recapture rates. We used the first 2 principal components, comprising 30 and $19 \%$, respectively, of the total variance among the included covariates. The first component mainly integrated variation of the SOI and ice conditions in the WAP, while the second component integrated ice conditions in the Weddell Sea.

Once the best generic models of survival and a recapture were selected, each environmental covariate was substituted for the generic time-dependent effect in models for survival and recapture probability. This procedure allowed an analysis of deviance to estimate the proportion of deviance in the full CMR model explained by each covariate (a deviance $\mathrm{R}^{2}$; Grosbois et al. 2008) in isolation from the other indices that have been identified as important drivers of population dynamics. We compared the fit of the generic time-varying model and each environmental covariate model with respect to a constant model. For this analysis, the constant model excluded time effects from the best generic models, but retained bandand trap-dependence effects. We also report correlation coefficients between the modeled estimates of survival rates and de-trended environmental covariates. This correlative approach provided a check on the relationship between environmental covariates and the estimated survival rates. 


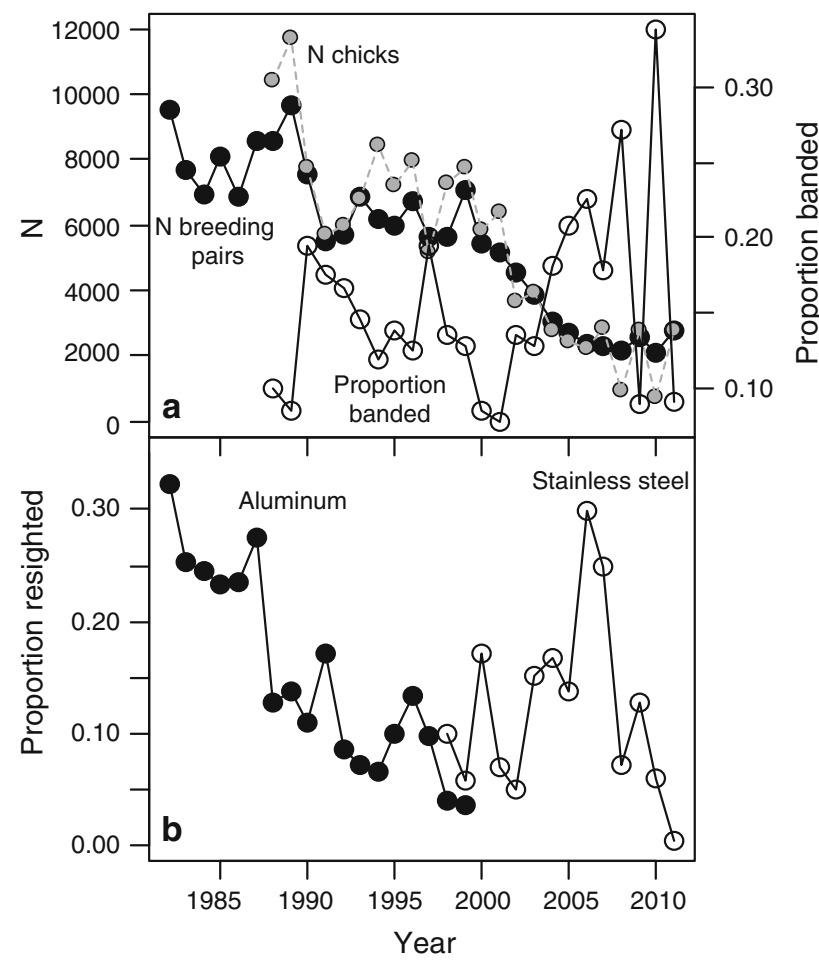

Fig. 2 a Total number of $P$. adeliae breeding pairs (closed circles) in the Copacabana colony and the proportion of chicks (age 0 ) tagged relative to total breeding pairs (open circles) during the study period. b Proportion of banded individuals that were ever resighted at the natal colony for individuals with either aluminum (closed circles) or stainless steel (open circles) flipper bands. Recruitment for cohorts banded from 2009 to 2011 remains incomplete

\section{Results}

Summary of banding data

In total, 15,033 chicks with aluminum bands were released between 1982 and 1999, while 6,248 chicks with stainless steel bands were released between 1998 and 2012. Relative to annual estimates of chick production, tagging rates averaged $15.5 \%(\mathrm{SD}=0.06)$ and ranged from 8 to $34 \%$ (Fig. 2a). Return rates of bands from each cohort ranged from 5 to $30 \%$ (Fig. 2b), but note the limited number of years available to judge total returns for the cohorts released since 2010. On average, $14.5 \%$ of all releases from each year were recaptured $(\mathrm{SD}=0.08)$; 2,099 individuals with aluminum bands and 794 individuals with stainless steel bands were resighted in their natal colony at least once by February 2012. The proportion of each banded cohort that was recaptured declined from 1985 through 1999, followed by an apparent increase in return rates through the early 2000s (Fig. 2b).

The proportional return rates differed by band type. When both band types were released at the same time in
1998 and 1999, the return rates of birds with stainless steel bands were higher than the return rate of birds with aluminum bands (Fig. 2b). The independent tag retention study with doubly tagged individuals and the adult breeder return rate with singly tagged individuals (Online Resource 1) suggested that stainless steel bands had a higher retention rate and return rates than aluminum bands, respectively. Estimates of survival and recapture probability may therefore differ by band type, supporting the inclusion of an effect for band type in the CMR models.

Capture-mark-recapture models

Bootstrapped estimates of the deviance in the global CMR model $\left(\varphi_{a * t+\text { band }} * p_{a * t+\text { band }}\right)$ suggested a lack of fit between the model and data $(\hat{c}=2.0)$. However, this amount of over dispersion is within the acceptable range for model comparison (Lebreton et al. 1992) and model selection proceeded with quasi-likelihoods and smallsample-corrected quasi-AIC criteria $\left(\mathrm{QAIC}_{\mathrm{c}}\right.$, White and Burnham 1999).

Of the models considered, a 2 age-class model and an additive effect of band type for survival $\left(\varphi_{\text {ac } 1 * t+\text { band }}\right)$ and a 3 age-class model with additive effects of time and trap dependence for recapture probability $\left(p_{\mathrm{ac} 2+\mathrm{time}+t d}\right)$ were selected as the most parsimonious, collecting $44 \%$ of the $\mathrm{QAIC}_{\mathrm{c}}$ weight (Table 1). This model was also selected first among all alternative models for values of $\hat{c}$ ranging from 1.5 to 2.5. Across a broad range of overdispersion, the selection of this model for further analysis appears justified.

The best model suggested that survival rates of the Adélie penguin population in Admiralty Bay were best characterized by a juvenile age class (age 0-2) and an adult age class (age 2+) only. The model further indicated that birds banded with stainless steel bands had higher apparent survival rates relative to those banded with aluminum bands, consistent with different band loss rates observed in the double banding study (Online Resource 1). Despite the negative bias introduced by aluminum bands, survival rates of juveniles marked with aluminum bands declined from 1982 through $2000\left(F_{1,15}=4.69, P=0.04\right)$. Survival rates of the cohorts banded with stainless steel bands since 1997 exhibited no trends $\left(F_{1,11}=0.14, P=0.71\right.$; Fig. $\left.3 \mathrm{a}\right)$. On average, juvenile survival rates were estimated to be $0.50 \pm 0.16$. Note that the model estimates of survival rates for the juvenile age class in 1982, 1987, and 2001 were at the boundary of 1 with standard errors equal to the interval $[0,1]$; these poorly estimated survival rates were removed for subsequent analyses.

Apparent survival rates for adult birds (Fig. 3b) exhibited no linear trends for aluminum $\left(F_{1,18}=2.77\right.$, $P=0.11)$ or stainless steel bands $\left(F_{1,10}=0.01, P=0.94\right)$ 
Table 1 Model selection table for survival $(\varphi)$ and recapture $(p)$ probabilities estimated for Adélie penguins ( $P$. adeliae $)$

Models are ranked according to $\Delta \mathrm{QAIC}_{\mathrm{c}}$ based on $\hat{c}=2$. Model rankings assuming a range of alternative values for $\hat{c}$ are provided. Age-class (ac) models are as described in the text

\begin{tabular}{|c|c|c|c|c|c|c|c|c|}
\hline \multirow{2}{*}{$\begin{array}{l}\text { Survival model: } \\
\phi\end{array}$} & \multirow[t]{2}{*}{ Recapture model: $p$} & \multirow[t]{2}{*}{$N$ pars } & \multirow[t]{2}{*}{$\Delta \mathrm{QAIC}_{\mathrm{c}}$} & \multirow{2}{*}{$\begin{array}{l}\text { QAIC }_{c} \\
\text { weight }\end{array}$} & \multicolumn{4}{|c|}{ Alternative $\hat{c}$} \\
\hline & & & & & 1.5 & 1.75 & 2.25 & 2.5 \\
\hline ac1:time + band & $\mathrm{ac} 2+$ time $+\mathrm{td}$ & 92 & 0 & 0.44 & 1 & 1 & 1 & 1 \\
\hline ac1:time + band & ac $2+$ time + band + td & 93 & 1.64 & 0.19 & 2 & 2 & 2 & 2 \\
\hline ac1:time + band & $\mathrm{ac} 3+$ time $+\mathrm{td}$ & 93 & 1.98 & 0.16 & 3 & 3 & 3 & 3 \\
\hline ac1:time & $\mathrm{ac} 2+$ time + band + td & 92 & 3.01 & 0.09 & 5 & 4 & 4 & 4 \\
\hline ac1:time + band & ac $3+$ time + band + td & 94 & 3.61 & 0.07 & 4 & 5 & 5 & 5 \\
\hline ac1:time & ac $3+$ time + band + td & 93 & 5.02 & 0.04 & 6 & 6 & 6 & 6 \\
\hline ac2:time & ac $2+$ time + band + td & 91 & 13.49 & 0.001 & 13 & 7 & 7 & 7 \\
\hline ac2:time + band & ac2 + time + band + td & 92 & 14.18 & 0.0003 & 15 & 8 & 8 & 8 \\
\hline ac2:time & ac $3+$ time + band + td & 92 & 14.68 & 0.0003 & 17 & 10 & 9 & 9 \\
\hline ac2:time + band & $\mathrm{ac} 2+$ time $+\mathrm{td}$ & 91 & 15.41 & 0.0002 & 21 & 16 & 10 & 10 \\
\hline
\end{tabular}

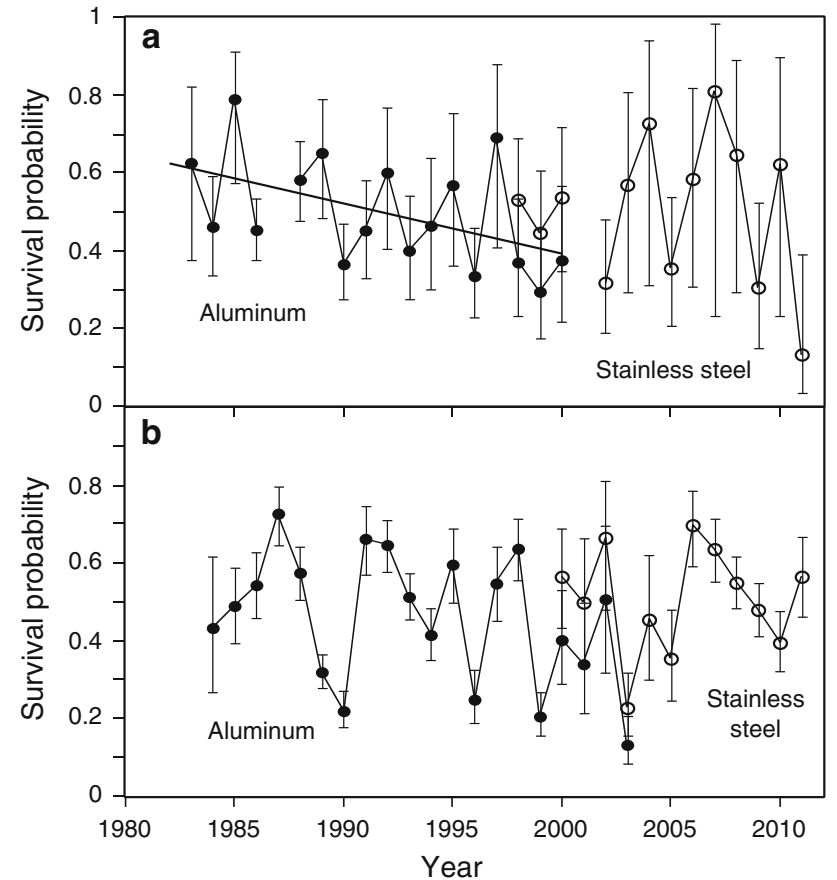

Fig. 3 Survival rates of juvenile and adult $P$. adeliae. a Estimates \pm SE of apparent survival rates from the best-fitting model for juvenile Adélie penguins (age 0-2) with aluminum (closed circles) and stainless steel bands (open circles). b Estimates \pm SE of apparent survival rates from best-fitting model for adult $P$. adeliae (age 2+) with aluminum (closed circles) and stainless steel bands (open circles). The linear decline in juvenile survival rates for years when aluminum bands were used is plotted. Note that juvenile survival rates in 1982, 1987, and 2001 were not estimable from the data

and averaged $0.48 \pm 0.15$. Despite similar mean values, adult and juvenile survival rates were not highly correlated for birds with aluminum bands $\left(r=0.4, t_{14}=1.64\right.$, $P=0.12)$ or stainless steel bands $\left(r=-0.01, t_{9}=-0.03\right.$, $P=0.97)$. The main feature among the adult survival rates was a strong fluctuation between relatively low and high values. Notably, a two-year span of low apparent survival

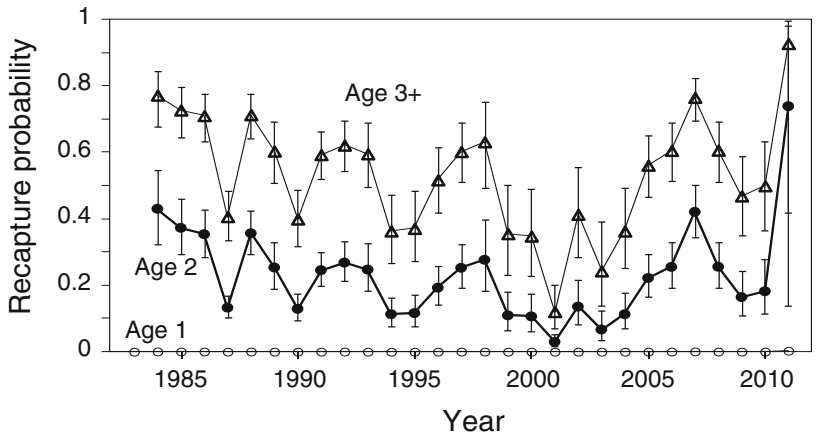

Fig. 4 Estimates $\pm \mathrm{SE}$ of recapture probability for $P$. adeliae from the best-fitting model with 3 age classes: age 1 (open circle); age 2 (closed circle), age $3+$ (open triangle)

rates among adults in 1989 and 1990 corresponded to the roughly $50 \%$ decline in the breeding population between 1989 and 1991 (Fig. 2a). Adult survival rates since that population crash remained highly variable.

Recapture probability of age 1 animals was estimated to be near 0 , (Fig. 4) consistent with very low proportions of animals ever seen as age 1, and recapture probability increased in older age classes. An additive effect of time was found to be important, such that recapture probabilities were time varying, but that recapture of all age classes was subject to the same time effect. This suggests a common effect on return rates of animals to the study colony. An additive effect of trap dependence was also included in the best-fitting model and suggested individuals recaptured previously were more likely to be recaptured again. Based on the most parsimonious model, band type did not appear to affect recapture rates. The second best model (Table 1) did include an effect of band type on recapture probability, but a likelihood ratio test between the top 2 models $\left(\chi^{2}=\right.$ $0.58, P=0.53)$ suggests the more parsimonious recapture model without the band affect adequately described the 
Table 2 Percent of deviance in survival $(\varphi)$ and recapture $(p)$ rates accounted for by environmental covariates

\begin{tabular}{lc}
\hline Index & $\%$ Deviance \\
\hline Ice-WAP-Autumn & 29.1 \\
Ice-WS-Spring & 27.8 \\
Precipitation & 10.0 \\
Ice-WAP-Winter & 9.0 \\
PCA1 & 8.7 \\
Ice-WS-Autumn & 5.6 \\
SOI & 5.6 \\
PCA2 & 5.1 \\
Ice-WAP-Spring & 3.7 \\
Temperature & 1.9 \\
Ice-WS-Winter & 0.4 \\
SAM & 0
\end{tabular}

SOI Southern Oscillation Index, SAM mean winter (June-August) values for the Southern Annular Mode, PCA 1 and PCA 2 are the first and second principal components for the standardized environmental variables. Ice indices are for the Weddell Sea (WS) or western Antarctica Peninsula (WAP) region for 3-month austral seasons of autumn (March-May), winter (June-August), or spring (SeptemberNovember)

data. In general, recapture probabilities declined from the mid-1980s to the late 1990s when aluminum bands were used. Since 2000, recapture probabilities appear to have increased.

\section{Environmental correlates of survival}

Less than $30 \%$ of the variability evident in apparent survival and recapture probabilities was explained by any single index of environmental conditions or the multivariate index derived from the principal components analysis (Table 2). Sea ice extent anomalies in the WAP during autumn months and in the Weddell Sea during spring months each explained equivalent percentages of variation in survival and recapture rates, explaining roughly 29 and $28 \%$ of the model deviance, respectively. All other indices of the selected environmental conditions provided little explanatory power for understanding variation in survival and recapture rates.

A correlation analyses between the environmental indices and the estimates of juvenile and adult survival rates generally agreed that sea ice provided an important correlate of Adélie penguin survival. However, the correlations also indicate that the temporal and spatial scope of sea ice conditions examined is important. In particular, adult survival rates generally exhibited positive correlations with sea ice extent during the non-breeding season but were most strongly correlated with sea ice extent in the Weddell Sea during spring months $(r=0.62)$ and the
Table 3 Correlation coefficients for the relationship between estimated survival $(\varphi)$ probabilities of Adélie penguins (P. adeliae) and select environmental variables

\begin{tabular}{|c|c|c|c|c|c|}
\hline Stage & Covariate & $r$ & $T$ & $d f$ & $P$ \\
\hline \multirow[t]{12}{*}{ Adult } & Ice-WS-Spring & 0.62 & 4.03 & 26 & 0.004 \\
\hline & Ice-WAP-Autumn & 0.49 & 2.88 & 26 & 0.0078 \\
\hline & PCA1 & -0.46 & -2.61 & 26 & 0.0150 \\
\hline & Ice-WAP-Winter & 0.40 & 2.21 & 26 & 0.0360 \\
\hline & Temperature & -0.39 & -2.19 & 26 & 0.0378 \\
\hline & SOI & -0.30 & -1.62 & 26 & 0.1171 \\
\hline & Precipitation & 0.28 & 1.50 & 26 & 0.1449 \\
\hline & PCA2 & -0.28 & -1.47 & 26 & 0.1541 \\
\hline & Ice-WS-Winter & 0.16 & 0.82 & 26 & 0.4182 \\
\hline & Ice-WS-Autumn & -0.07 & -0.35 & 26 & 0.7319 \\
\hline & SAM & -0.05 & -0.28 & 26 & 0.7837 \\
\hline & Ice-WAP-Spring & -0.03 & -0.14 & 26 & 0.8875 \\
\hline \multirow[t]{12}{*}{ Juvenile } & Ice-WS-Winter & 0.46 & 2.56 & 25 & 0.0169 \\
\hline & PCA2 & -0.45 & -2.53 & 25 & 0.0183 \\
\hline & Ice-WAP-Spring & -0.41 & -2.26 & 25 & 0.0326 \\
\hline & Ice-WAP-Winter & -0.32 & -1.71 & 25 & 0.0999 \\
\hline & Ice-WS-Autumn & 0.27 & 1.40 & 25 & 0.1741 \\
\hline & SAM & 0.23 & 1.21 & 25 & 0.2387 \\
\hline & PCA1 & 0.23 & 1.18 & 25 & 0.2486 \\
\hline & Ice-WS-Spring & 0.20 & 1.05 & 25 & 0.3050 \\
\hline & Temperature & 0.18 & 0.92 & 25 & 0.3643 \\
\hline & Precipitation & 0.11 & 0.57 & 25 & 0.5745 \\
\hline & Ice-WAP-Autumn & -0.08 & -0.41 & 25 & 0.6854 \\
\hline & SOI & -0.06 & -0.30 & 25 & 0.7658 \\
\hline
\end{tabular}

SOI Southern Oscillation Index, SAM mean winter (June-August) values for the Southern Annular Mode, PCA 1 and PCA 2 are the first and second principal components for the standardized environmental variables. Ice indices are for the Weddell Sea (WS) or western Antarctica Peninsula (WAP) region for 3-month austral seasons of autumn (March-May), winter (June-August), or spring (SeptemberNovember). A Bonferoni-corrected critical $P$ value is 0.003

WAP in autumn ( $r=0.49$; Table 3; Fig. 5). Juvenile survival rates were positively correlated with sea ice extent in the Weddell Sea during autumn months ( $r=0.46$, Fig. 5), but exhibited negative relationships of similar magnitude with sea ice extent anomalies in the WAP region at other times of the year (Table 3). Due to multiple comparisons, a conservative Bonferroni adjustment of critical $P$ values suggests that the only statistically significant correlation evident in these data was between adult survival rates and Weddell Sea ice index in spring (Table 3).

\section{Discussion}

Population growth rates in long-lived animals ought to be sensitive to variation in adult survival rates (Lebreton and 

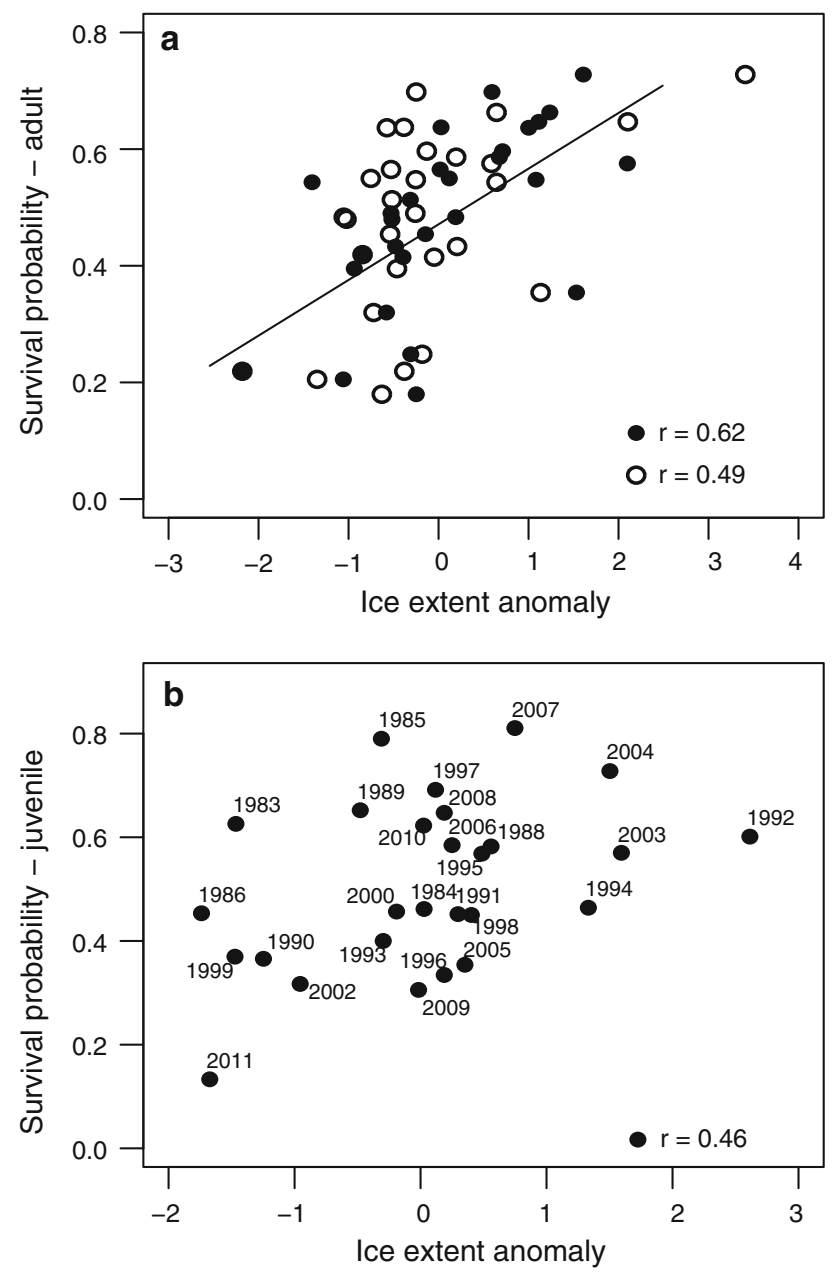

Fig. 5 Relationship between $P$. adeliae survival rates and sea ice extent anomalies. a Positive relationship of adult survival rates to sea ice extent in the Weddell Sea during spring (September-November, closed circle) and the western Antarctic Peninsula region during autumn (March-May, open circle). b Positive relationship of juvenile survival rates to sea ice extent in the Weddell Sea during winter (June-August, closed circle); labels identify the year for each point

Clobert 1991). Consequently, seabirds typically exhibit low variability in adult survival rates (Sæther and Bakke 2000). During a period of population decline among Adélie penguins in the South Shetland Islands (Lynch et al. 2008; Trivelpiece et al. 2011), survival rates of banded Adélie penguins declined among juveniles, while both juvenile and adult age classes were characterized by strong variability, ranging from survival rates from $<30$ to $>70 \%$. On average, adult survival rates were equivalent to average juvenile survival rates (ca. $50 \%$ ). Such low adult survival rates, coupled with high interannual variability, help explain the rapid decline of the breeding population in the study colony. In particular, two consecutive years of poor adult survival (ca. $30 \%$ ) corresponded to the near $50 \%$ decline in breeding population abundance from 1989 to
1991. On the whole, long-term declines in the breeding population of Adélie penguins in Admiralty Bay were concurrent with declines in juvenile survival rates and appear to be influenced by the high degree of variability in adult survival rates. The available evidence also suggests that the variability in survival rates is positively related to sea ice extent in the Weddell Sea and WAP regions, but a majority of the variation in survival rates remains unexplained by single environmental indices, particularly for juvenile Adélie penguins.

Hinke et al. (2007) reported a declining trend in recruitment of young Adélie penguins to the natal colony and, based on analyses of summer reproductive indices, suggested that overwinter survival of juvenile penguins could be a factor affecting the decline in the population. It is important to note that Hinke et al. (2007) examined recruitment as a proportional return rate, modified for band loss, for all animals between the ages of 0 and 5 combined. Here, the CMR model identified an age class of juveniles that included only immature individuals (age 0-2) as the juvenile age class. Despite the different operational definitions of 'juvenile' and the analytic methods used in both studies, the results indicate that juvenile survival rates declined during the 1980s and 1990s.

We posit that the negative trend in juvenile survival accelerated the decline in the breeding population. Supporting evidence for this is twofold. First, a shrinking breeder population resulted in reduced total chick production in the colony over time; per capita chick production during the period of population decline exhibited no compensatory response (Hinke et al. 2007). Higher mortality rates among the progressively fewer juveniles would have reduced the size of the juvenile population necessary to replenish the declining breeding population. As a result of increasing juvenile mortality rates, consistently large recruitment events into the breeding population that occurred in the early 1980s (Fig. 2b) were not observed during the period of population decline. Second, after 2000, the negative trend in juvenile survival ceased, while return rates and recapture probabilities increased. These events were coincident with a stabilization of the breeding population around roughly 2400 pairs, despite a continued high variability in adult survival rates. It appears that while variability in adult survival rates represents the primary control on the rate of decline in the breeding population, the stabilization of the juvenile survival rates since the early 2000s helped reduce the rate of change in the breeding population. A positive correlation between midwinter (June-August) ice extent anomalies in the Weddell Sea and juvenile survival rates suggests that the relatively frequent occurrence of positive ice anomalies since 2000 (Fig. 5b) may have contributed to this stabilization of juvenile survival. 
Complex environmental effects on Adélie penguin survival

Large-scale atmospheric indices and associated regional changes in marine conditions have been implicated in trends in numerous seabird populations around the world (Veit et al. 1996; Croxall et al. 2002; Sandvik et al. 2005; Devney et al. 2009). In Antarctica, the responses of penguin populations to environmental variability have included changes in abundance (e.g., Trathan et al. 1996; Wilson et al. 2001), but also included shifts in range (Emslie et al. 1998), changes in breeding phenology (Barbraud and Weimerskirch 2006; Hinke et al. 2012), and changes in foraging behavior (Fraser and Hofmann 2003). Despite major changes in environmental conditions in the Antarctic Peninsula region (Turner et al. 2005a; Stammerjohn et al. 2008a; Meredith and King 2005), the majority of interannual variation in survival rates of Adélie penguins was not well explained by the selected indices of environmental conditions.

The relatively weak effects of environmental conditions on survival rates of Adélie penguins in the northern Antarctic Peninsula region contrast with results of demographic studies of Adélie penguins from more southern locales. There, stronger effects of winter sea ice and largescale atmospheric drivers, like the SOI, on survival rates (Jenouvrier et al. 2006; Ballerini et al. 2009; Emmerson and Southwell 2011) have been reported. To understand such differences, it is useful to consider how the two systems differ. Perhaps the most important difference between the southern and northern regions is the prevalence and seasonal variation in sea ice. Since the mid-1970s, the winter sea ice season has declined in the WAP and the northwestern margins of the Weddell Sea, whereas sea ice extent in the Ross Sea, eastern Weddell Sea, and along east Antarctica has grown or remained relatively stable (Stammerjohn et al. 2008b). For animals dependent on sea ice habitats, particularly the marginal ice zone of loosely aggregated pack ice that is typically used by Adélie penguins during winter (Ainley 2002), shifts in the duration and spatial extent of ice coverage during winter are expected to be important drivers of population change whereby too little or too much ice may be detrimental to survival (e.g., Emmerson and Southwell 2011). The positive correlation observed between ice extent and adult survival rates in the Antarctic Peninsula region supports the expectation that a loss of sea ice reduces penguin's survival. However, relationships between survival rates and rapidly changing environmental conditions in the Antarctic Peninsula region may be more complex than linear models and single indices may suggest.

Shifting environmental conditions (and any synergistic interactions among them) can make predicting the response of species difficult (e.g., Folke et al. 2004; Brook et al. 2008), and the Antarctic Peninsula region is among the most rapidly changing areas on earth. One possible result of the loss of critical sea ice habitat in the northern part of the Adélie range is an elevated importance of alternative drivers that affect variation in survival rates. For example, food web changes in the southern Scotia Sea that are associated with commercial krill fisheries, increased competition for prey due to the recovery of once-depleted marine mammal populations, and overall declines in preferred prey (Atkinson et al. 2004; Trivelpiece et al. 2011) may interact with ENSO events, reductions in sea ice extent, or local weather conditions to affect survival rates in nonlinear, complex ways. Such interactions could dampen the signal of a single index of environmental conditions, but are difficult to identify with standard CMR models.

Trivelpiece et al. (2011) proposed that the changes in the Adélie penguin populations in the WAP region derived from the dynamic linkage between krill biomass and the variable winter sea ice conditions that directly affect krill recruitment dynamics. With respect to the survival rates reported here, the early period of decline in juvenile penguin survival rates in the 1980s may be linked with declines of krill biomass in the early 1980s that resulted from a decreased frequency of years with extensive winter sea ice. Fraser et al. (1992) noted that the early 1980s represented the first prolonged period of relatively warm temperatures with reduced ice cover during winter in the Antarctic Peninsula region. Such low ice conditions are thought to negatively affect the distribution, fecundity, and survival of krill and may have precipitated the episodic recruitment and subsequent senescence of single krill cohorts that are evident throughout the 1990s and 2000s (Fraser and Hofmann 2003; Reiss et al. 2008). Reduced krill availability at a time with relatively high krilldependent Adélie populations in the late 1970s and early 1980s (Trivelpiece et al. 2011) may have set the stage for a downward adjustment to population size via higher mortality rates among penguins. However, such food web linkages can be enormously difficult to quantify, particularly on the spatial scales relevant to the foraging and overwinter distributions of ice-obligate Adélie penguins. Current survey work in the WAP region during winter months (US AMLR Program, unpublished data) may help to identify appropriate indices of winter food availability to include in modeling exercises to test this hypothesis.

It is also worth noting that the estimated adult and juvenile survival rates, while similar in magnitude, were not correlated in this study. Indeed, different time periods of sea ice anomalies (winter vs. spring) were most strongly correlated with the estimates of juvenile and adult survival rates, respectively. Similarly, Emmerson and Southwell 
(2011) reported that adult survival rates in east Antarctica were best explained by the extent of sea ice in winter foraging grounds, but juvenile survival rates were best explained by the extent of sea ice area during the return migration to natal colonies. They concluded that environmental conditions that impact survival may be age specific and our results agree. These studies highlight how populations from different regions can respond differently to the same environmental indices and suggest that such regional differences in the demographic response to environmental conditions should be accounted for when modeling population dynamics. In particular, attempts to predict circumpolar population changes (e.g., Jenouvrier et al. 2014) would be improved by understanding the spatial and temporal scale of environmental indices that affect demographic rates at multiple study sites.

Factors other than environmental conditions may also impact differential survival of adults and juvenile penguins. The first winter of independence is widely considered an important bottleneck for survival among juvenile penguins due to their limited foraging experience in a marine environment (Ainley 2002). There, variation in local food availability following the breeding season or changes in predation risk from leopard seals (Hydruga leptonyx) and other marine mammals (e.g., Ciaputa and Siciński 2006; Pitman and Durban 2010) may lower survival rates of juveniles immediately following the fledging period independent of environmental conditions. Such differing demographic vulnerabilities to survival complicate the assessment of definitive drivers of population change.

\section{Band retention and potential negative bias on survival estimates}

The use of flipper bands on penguins for individual identification and demographic studies has a long and checkered history. Deleterious effects of flipper bands are well known and include increased energy expenditure, reduced reproductive success, and reduced survival rates (Culik et al. 1993; Froget et al. 1998; Gauthier-Clerc et al. 2004; Dugger et al. 2006). Others report little to no effect of properly designed and attached bands (Hindell et al. 1996; Boersma and Rebstock 2009). With respect to the estimation of survival rates, increased mortality rates that arise from the presence of the band or the loss of flipper bands from the marked population are an important source of potential bias. Here, the double banding study (Online Resource 1) conducted during two field seasons indicated that band retention rates of aluminum bands were much lower than for stainless steel bands. Furthermore, the modeling results indicated that birds with aluminum bands exhibited lower survival rates relative to animals with stainless steel bands. Together, the results suggest that the estimates of survival from the banded population of longlived Adélie penguins were biased low. Indeed, Ballerini et al. (2009) noted that estimates of survival made from flipper bands were generally lower than estimates made with other marking techniques, like passive integrated transponders. The possibility that such band effects also mediate the influence of environmental drivers may also exist. For example, band effects may be minor or absent under normal conditions, but become deleterious under adverse conditions. Such an affect was reported for Adélie penguins in the Ross Sea, where banded birds had lower survival rates in the presence of grounded icebergs that precluded access to preferred foraging grounds (Dugger et al. 2010). At worst, such sensitivity to flipper bands could undermine the accuracy of results that relate survival rates to large-scale environmental indices, thus explaining the poor predictive power of several environmental indices examined here. However, the estimated survival and recapture rates were consistent with the overall trends in the population and with the recruitment indices of Hinke et al. (2007). Despite a negative bias, we maintain that the overall results from a long-term banding program remain valid, namely that a high degree of variation in adult survival rates and a decline in juvenile survival and recruitment in the 1980s and 1990s, partially driven by changes in sea ice extent in the WAP and Weddell Sea appear responsible for the rapid decline in the population of Adélie penguins in Admiralty Bay and throughout the northern Antarctic Peninsula region.

\section{Conclusion}

Recent studies in seabirds have demonstrated how increased variance in survival rates due to environmental variability can drive population declines (Frederiksen et al. 2008; Jenouvrier 2009). A hallmark of model predictions for future climate change in the Antarctic includes continued directional change, but also increases in climate variation and extreme events (Solomon et al. 2007). If such events cause the frequency of years with poor survival rates to increase, accelerated population decline may occur. This prediction can be tested with a demographic model of population dynamics (e.g., Jenouvrier et al. 2009) and is the focus of the ongoing research.

Acknowledgments Many thanks to numerous field biologists whose commitment to long-term observations in the Antarctic made this study possible. Financial support was generously provided by numerous National Science Foundation grants to W.Z.T. and SGT between 1980 and 2010 and J.T.H. was supported by the Lenfest Oceans Program at the Pew Charitable Trusts. All studies were conducted with under approved UCSD Institutional Animal Care and Use Committee permits to W.Z.T. Comments by G. Kooyman, J. 
Laake, and M. Goebel and three anonymous reviewers improved this manuscript.

Open Access This article is distributed under the terms of the Creative Commons Attribution License which permits any use, distribution, and reproduction in any medium, provided the original author(s) and the source are credited.

\section{References}

Ainley DG (2002) The Adélie penguin: bellwether of climate change. Columbia University Press, New York

Ainley D, Russell J, Jenouvrier S, Woehler E, Lyver PO, Fraser WR, Kooyman GL (2010) Antarctic penguin response to habitat change as Earth's troposphere reaches $2^{\circ} \mathrm{C}$ above preindustrial levels. Ecol Monogr 80:49-66

Akaike H (1973) Information theory and an extension of the maximum likelihood principle. In: Petran BN, Csaki F (eds) International symposium on information theory, 2nd edn. Akadémiai Kiadi, Budapest, pp 267-281

Atkinson A, Siegel V, Pakhomov E, Rothery P (2004) Long-term decline in krill stock and increase in salps within the Southern Ocean. Nature 432:100-103

Ballerini T, Tavechia G, Olmastroni S, Pezzo F, Focardi S (2009) Nonlinear effects of winter sea ice on the survival probabilities of Adélie penguins. Oecologia 161:253-265

Barbraud C, Weimerskirch H (2006) Antarctic birds breed later in response to climate change. Proc Natl Acad Sci USA 103:6248-6251

Boersma PD (2008) Penguins as marine sentinels. Bioscience 58:597-607

Boersma PD, Rebstock GA (2009) Flipper bands do not affect foraging-trip durations of Magellanic penguins. J Field Ornithol 80:408-418

Brook BW, Sodhi NS, Bradshaw CJA (2008) Synergies among extinction drivers under global change. Trends Ecol Evol 23:453-460

Cavalieri DJ, Parkinson CL (2008) Antarctic sea ice variability and trends, 1979-2006. J Geophys Res 113. doi:10.1029/2007 JC004564

Cavalieri DJ, Parkinson CL, Gloerson P, Comiso JC, Zwally HJ (1999) Deriving long-term time series of sea ice cover from satellite passive-microwave multisensory data sets. J Geophys Res 104(C7):15803-15814

Ciaputa P, Siciński J (2006) Seasonal and annual changes in Antarctic fur seal (Arctocephalus gazella) diet in the area of Admiralty Bay, King George Island, South Shetland Islands. Pol Polar Res 27:171-184

Clarke J, Kerry K, Fowler C, Lawless R, Eberhard S, Murphy R (2003) Post-fledging and winter migration of Adélie penguins Pygoscelis adeliae in the Mawson region of East Antarctica. Mar Ecol Prog Ser 248:267-278

Cooch E, White G (2013) Program MARK: a gentle introduction, 13 ed. http://www.phidot.org/software/mark/docs/book/

Croxall JP, Trathan PN, Murphy EJ (2002) Environmental change and Antarctic seabird populations. Science 297:1510-1514

Culik B, Wilson RP, Bannasch R (1993) Flipper-bands on penguins: what is the cost of a life-long commitment? Mar Ecol Prog Ser 98:209-214

Devney CA, Short M, Congdon BC (2009) Sensitivity of tropical seabirds to El Niño precursors. Ecology 90:1175-1183

Dugger KM, Ballard G, Ainley DG, Barton KJ (2006) Effects of flipper bands on foraging behavior and survival of Adélie penguins (Pygoscelis adeliae). Auk 123:858-869
Dugger KM, Ainley DG, Lyver PO, Barton K, Ballard G (2010) Survival differences and the effect of of environmental instability on breeding dispersal in an Adélie penguin metapopulation. Proc Natl Acad Sci USA 107:12375-12380

Emmerson L, Southwell C (2011) Adélie penguin survival: age structure, temporal variability and environmental influences. Oecologia 167:951-965

Emslie SD, Fraser W, Smith RC, Walker W (1998) Abandoned penguin colonies and environmental change in the Palmer Station area, Anvers Island, Antarctic Peninsula. Antarct Sci $10: 257-268$

Folke C, Carpenter S, Walker B, Scheffer M, Elmqvist T, Gunderson L, Holling CS (2004) Regime shifts, resilience, and biodiversity in ecosystem management. Ann Rev Ecol Syst 35:557-581

Forcada J, Trathan PN (2009) Penguin responses to climate change in the Southern Ocean. Glob Chang Biol 15:1618-1630

Fraser WR, Hofmann EE (2003) A predator's perspective on causal links between climate change, physical forcing and ecosystem response. Mar Ecol Prog Ser 265:1-15

Fraser WR, Trivelpiece WZ, Ainley DG, Trivelpiece SG (1992) Increases in Antarctic penguin populations: reduced competition with whales or a loss of sea ice due to environmental warming? Polar Biol 11:525-531

Frederiksen M, Daunt F, Harris MP, Wanless S (2008) The demographic impact of extreme events: stochastic weather drives survival and population dynamics in a long-lived seabird. J Anim Ecol 77:1020-1029

Froget G, Gautier-Clerc M, Le Maho Y, Handrich Y (1998) Is penguin banding harmless? Polar Biol 20:409-413

Gauthier-Clerc M, Gendner JP, Ribic CA, Fraser WR, Woehler EJ, Descamps S, Gilly C, Le Bohec C, Le Maho Y (2004) Long-term effects of flipper bands on penguins. Proc R Soc Lond B 271:S431-S436

Grosbois V, Gimenez O, Gaillard J-M, Pradel R, Barbraud C, Clobert J, Møller AP, Weimerskirch H (2008) Assessing the impact of climate variation on survival in vertebrate populations. Biol Rev Camb Philos Soc 83:357-399

Hewitt RP (1997) Areal and seasonal extent of sea-ice cover off the northwestern side of the Antarctic Peninsula: 1979 to 1996. CCAMLR Sci 4:65-73

Hindell MA, Lea MA, Hull CL (1996) The effects of flipper bands on adult survival rate and reproduction in the Royal Penguin, Eudyptes schlegeli. Ibis 138:557-560

Hinke JT, Salwicka K, Trivelpiece SG, Watters GM, Trivelpiece WZ (2007) Divergent responses of Pygoscelis penguins reveal a common environmental driver. Oecologia 153:845-855

Hinke JT, Polito MJ, Reiss CS, Trivelpiece SG, Trivelpiece WZ (2012) Flexible reproductive timing can buffer reproductive success of Pygoscelis penguins in the Antarctic Peninsula region. Mar Ecol Prog Ser 454:91-104

Jenouvrier S, Barbraud C, Weimerskirch H (2005) Long-term contrasted responses to climate of two Antarctic seabird species. Ecology 86:2889-2903

Jenouvrier S, Barbraud C, Weimerskirch H (2006) Sea ice affects the population dynamics of Adélie penguins in Terre Adélie. Polar Biol 29:413-423

Jenouvrier S, Caswell H, Barbraud C, Holland M, Strœve J, Weimerskirch H (2009) Demographic models and IPCC projections predict the decline of an emperor penguin population. Proc Natl Acad Sci USA 106:1844-1847

Jenouvrier S, Holland M, Stroeve J, Serreze M, Barbraud C, Weimerskirch H, Caswell H (2014) Projected continent-wide declines of the emperor penguin under climate change. Nat Clim Chang 4:715-718

Kwok R, Comiso JC (2002) Spatial patterns of variability in Antarctic surface temperature: connections to the southern hemisphere 
annular mode and the Southern Oscillation. Geophys Res Lett 29:1-4. doi:10.1029/2002GL015415

Laake J (2013) RMark: an R interface for analysis of capturerecapture data with MARK. Alaska Fisheries Science Center, National Marine Fisheries Service, NOAA. AFSC Processed Report 2013-01

Lebreton JD, Clobert J (1991) Bird population dynamics, management, and conservation: the role of mathematical modeling. In: Perrins CM, Lebreton JD, Hirons GJM (eds) Bird population studies: relevance to conservation and management. Oxford University Press, Oxford, pp 105-125

Lebreton JD, Burnham KP, Clobert J, Anderson DR (1992) Modeling survival and testing biological hypotheses using marked animals: a unified approach with case studies. Ecol Monogr 62:67-118

Lescroël A, Dugger KM, Ballard G, Ainley DG (2009) Effects of individual quality, reproductive success and environmental variability on survival of a long-lived seabird. J Anim Ecol 78:798-806

Lynch HJ, Naveen R, Fagan WF (2008) Censuses of penguin, blueeyed shag Phalacrocorax atriceps and southern giant petrel Macronectes giganteus populations on the Antarctic Peninsula, 2001-2007. Mar Ornithol 36:83-97

Meredith MP, King JC (2005) Rapid climate change in the ocean west of the Antarctic Peninsula during the second half of the 20th century. Geophys Res Lett 32:L19604. doi:10.1029/2005GL024042

Montes-Hugo M, Dooney SC, Ducklow HW, Fraser W, Martinson D, Stammerjohn SE, Schofield O (2009) Recent changes in phytoplankton communities associated with rapid regional climate change along the western Antarctic Peninsula. Science 323:1470-1473

Nelson LJ, Anderson DR, Burnham KP (1980) The effect of band loss on estimates of annual survival. J Field Ornithol 51:30-38

Pitman R, Durban JW (2010) Killer whale predation on penguins in Antarctica. Polar Biol 33:158-1594

Pradel R (1993) Flexibility in survival analysis from recapture data: handling trap dependence. In: Lebreton JD, North PM (eds) Marked individuals in the study of bird population. Birkhäuser Verlag, Basel, pp 29-37

R Core Team (2012) R: a language and environment for statistical computing. R Foundation for Statistical Computing, Vienna, Austria. ISBN 3-900051-07-0. http://www.R-project.org/

Reiss CS, Cossio AM, Loeb V, Demer DA (2008) Variation in biomass of Antarctic krill (Euphausia superba) around the South Shetland Islands, 1996-2006. ICES J Mar Sci 65:497-508

Sæther B-E, Bakke $\varnothing$ (2000) Avian life history variation and contribution of demographic traits to the population growth rate. Ecology 81:642-653

Sandland RL, Kirkwood GP (1981) Estimation of survival in marked populations with possibly dependent sighting probabilities. Biometrika 68:531-541
Sandvik H, Erikstad KE, Barreett RT, Yoccoz NG (2005) The effects of climate on adult survival in five species of North Atlantic seabirds. J Anim Ecol 74:817-831

Stammerjohn SE, Martinson DG, Smith RC, Iannuzzi RA (2008a) Sea ice in the western Antarctic Peninsula region: spatio-temporal variability from ecological and climate change perspectives. Deep Sea Res Part II 55:2041-2058

Stammerjohn SE, Martinson DG, Smith RC, Yuan X, Rind D (2008b) Trends in Antarctic sea ice retreat and advance and their relation to $\mathrm{El}$ Niño-Southern Oscillation and Southern Annular Mode variability. J Geophys Res 113:C03S90. doi:10.1029/2007JC004269

Stearns SC (1992) The evolution of life histories. Oxford University Press, Oxford

Thomas ER, Marshall GJ, McConnell R (2008) A doubling of snow accumulation in the western Antarctic Peninsula since 1850. Geophys Res Lett 35:L01706. doi:10.1029/2007GL032529

Solomon S, Qin D, Manning M, Marquis M, Averyt K, Tignor, MMB, Miller HL Jr, Chen Z (eds) (2007) Climate Change 2007. The physical science basis. Contribution of Working Group I to the Fourth Assessment Report of the Intergovernmental Panel on Climate Change. Cambridge University Press, Cambridge

Trathan PN, Croxall JP, Murphy EJ (1996) Dynamics of Antarctic penguin population in relation to inter-annual variability in sea ice distribution. Polar Biol 16:321-330

Trivelpiece WZ, Hinke JT, Miller AK, Reiss CS, Trivelpiece SG, Watters GM (2011) Variability in krill biomass links harvesting and climate warming to penguin population sin Antarctica. Proc Natl Acad Sci USA 108:7625-7628

Turner J (2004) The El Niño-southern oscillation and Antarctica. Int J Climatol 24:1-31

Turner J, Colwell SR, Marshall GJ, Lachlan-Cope TA, Carleton AM, Jones PD, Lagun V, Reid PA, Iagovkina S (2005a) Antarctic climate change during the last 50 years. Int J Climatol 25:279-294

Turner J, Lachlan-Cope T, Colwell S, Marshall GJ (2005b) A positive trend in western Antarctic Peninsula precipitation over the last 50 years reflecting regional and Antarctic-wide atmospheric changes. Ann Glaciol 41:85-91

Turner J, Comiso JC, Marshall GJ, Lachlan-Cope TA, Bracegirdle T, Maksym T, Meredith MP, Wang Z, Orr A (2009) Non-annular atmospheric circulation change induced by stratospheric ozone depletion and its role in the recent increase of Antarctic sea ice extent. Geophys Res Lett 36. doi:10.1029/GL07524

Veit RR, Pyle P, McGowan JA (1996) Ocean warming and long-term change in pelagic bird abundance with the California current system. Mar Ecol Prog Ser 139:11-18

White GC, Burnham KP (1999) Program MARK: survival estimation from populations of marked animals. Bird Study 46(Suppl):120-139

Wilson PR, Ainley DG, Nur N, Jacobs SS, Barton KJ, Ballard G, Comiso JC (2001) Adélie penguin population change in the pacific sector of Antarctica: relation to sea ice extent and the Antarctic Circumpolar Current. Mar Ecol Prog Ser 213:301-309 